\title{
Investigation of the het genes that control heterokaryon incompatibility between members of heterokaryon-compatibility (h-c) groups A and G1 of Aspergillus nidulans
}

\author{
R. B. G. Dales*† and J. H. Croft $\ddagger$ \\ Department of Genetics, The University of Birmingham, PO Box 363, Birmingham B15 2TT, UK
}

(Received 13 February 1990; revised 13 April 1990; accepted 17 May 1990)

\begin{abstract}
A chromosome assay method was used to determine the heterokaryon compatibility relationships between strains belonging to heterokaryon-compatibility (h-c) groups A and G1 of Aspergillus nidulans. A hybrid strain (RD15) was isolated following protoplast fusion of strains 65-5 (h-cA) and 7-141 (h-cG1). The morphology of RD15 was severely abnormal compared to diploid strains of $\boldsymbol{A}$. nidulans produced from heterokaryon-compatible haploid parents. Inocula of RD15 were induced to haploidize on medium containing Benlate and a parasexual progeny sample of 291 haploid segregants was obtained. The progeny strains were genotyped for standard markers. Allelic ratios and pairwise marker segregations were determined. Pairs of progeny strains that carried different alleles for the standard markers on each linkage group in turn were tested for compatibility. Strain pairs that possessed different alleles for the markers on linkage groups II, III, V, VI and VII were incompatible indicating the presence of heterokaryon-incompatible (het) genes on these linkage groups. Backcrosses to an h-cGl strain showed that two het genes were located on linkage group III and confirmed a total of six het gene differences between the $h$-cA and h-cGl strains.
\end{abstract}

\section{Introduction}

Wild isolates of Aspergillus nidulans have been classified into heterokaryon-compatibility $(\mathrm{h}-\mathrm{c})$ groups based on whether mixed cultures form heterokaryotic mycelium (Grindle, 1963a,b). Compatibility tests can be done under selective or non-selective conditions. Selective methods usually require the prior introduction of selectable markers into isolates and conditions in which neither parental homokaryon can grow. Complementing nutritional requirements have been commonly used and selection can be imposed by inoculating the parental strains together onto minimal medium. Heterokaryotic mycelium grows out in a sectoring pattern, though mass hyphal subculture to fresh minimal medium may be necessary before such a growth habit is observed (Pontecorvo et al., 1953; Roper, 1966). Heterokaryonincompatible pairings, on the other hand, do not grow or show only limited growth from the initial centres of inoculation, even after subculture (Dales et al., 1983).

$\dagger$ Present address: Department of Biology, The University of the West Indies, Cave Hill Campus, PO Box 64, Bridgetown, Barbados.

$\ddagger$ Present address: School of Biological Sciences, The University of Birmingham, PO Box 363, Birmingham B15 2TT, UK.
Detection of heterokaryotic mycelium is helped by using parental strain combinations that differ for conidiospore colour. Heterokaryosis can then be detected by the sporadic occurrence within the mixed culture of individual conidiospore heads in which both parental spore colours are displayed in adjacent chains of spores. These mixed sporeheads have a vertically striped appearance (Pontecorvo et al., 1953) and indicate the heterokaryotic nature of the conidiophore vesicle from which the phialides and ultimately the conidial chains have been derived by mitosis. Observation of striped heterokaryotic sporeheads has been used as a definitive test for heterokaryon compatibility in $\boldsymbol{A}$. nidulans and is the basis for screening under non-selective conditions (Grindle, 1963a, $b$; Caten \& Jinks, 1966; Croft \& Jinks, 1977).

Using these methods 100 wild isolates of $A$. nidulans in the University of Birmingham strain collection have been assigned to $19 \mathrm{~h}-\mathrm{c}$ groups (h-cA, h-cB etc.) (Grindle, $1963 a, b$; Croft \& Jinks, 1977). None of these strains are compatible with the commonly held laboratory stocks of $A$. nidulans derived from NRRL 194 (Thom \& Raper, 1945) which have been assigned to a twentieth group (hcGl) (Croft \& Jinks, 1977). These heterokaryon compatibility differences do not disrupt the sexual cycle and pairs 
of heterokaryon-incompatible strains will readily form hybrid cleistothecia in the laboratory (Jinks et al., 1966; Butcher, 1968). Analysis of sexual cross progenies has indicated that heterokaryon incompatibility in $A$. nidulans is heterogenically controlled by a series of nuclear het genes. An allelic difference between parental strains at one or more het loci causes incompatibility (Croft \& Jinks, 1977).

Protoplast fusion has been used to produce somatic hybrids from heterokaryon-incompatible strains (Dales \& Croft, 1977, 1983; Dales et al., 1983). The colonies produced are often diffuse mycelial mats with sparse conidiation. Individual sporeheads are usually small, enclosed in an aqueous exudate and only rarely develop pigmentation. The hyphae, though, are often pigmented and sometimes this pigmentation is secreted into the surrounding medium. Analysis of colony morphology, stability and, more importantly, the segregation of genetical markers among breakdown sectors collected from hybrids has indicated that both heterokaryotic and diploid colonies can be isolated following protoplast fusion of heterokaryon-incompatible parental strains (Dales \& Croft, 1977, 1983; Dales et al., 1983). This has allowed the parasexual analysis of het genes. Two het loci, het $A$ and het $B$, were identified which segregated among haploid segregants obtained from a diploid formed between a strain belonging to $\mathrm{h}-\mathrm{cB}$ and an $\mathrm{h}-\mathrm{cGl}$ master strain (Dales et al., 1983). With two het genes segregating there were four progeny compatibility classes of which two were parental and two recombinant. The recombinant classes were composed of strains that differed from both parental h-c group strains at a single het locus. It was straightforward to observe how the parental markers segregated with each recombinant compatibility class and this indicated het gene locations for hetA and het $B$ on linkage groups $\mathrm{V}$ and VI, respectively (Dales et al., 1983).

Situations which involve more than two segregating het genes are much more difficult to analyse in this way, as it is not easy to generate the necessary compatibility tester strains. To avoid this problem a chromosome assay method has been used to investigate the haploid segregants obtained from a hybrid strain produced by protoplast fusion of an h-cQ strain with an h-cGl master strain (Dales \& Croft, 1983). The use of this method presumes complete linkage through the parasexual cycle of a het gene, or genes, and a marker gene located on the same chromosome. Pairs of parasexually derived progeny strains were selected that had alternative parental alleles for the marker on one linkage group, the linkage group under test, and identical alleles for the markers on the remaining linkage groups, with the exception of linkage group I. Heterozygosity for linkage group I was required to provide a spore colour difference. These strain pairs were compatibility tested. No het genes were detected on linkage group I. Consequently, a compatible result indicated there were no het gene differences, between the parental h-c group strains, on the linkage group under test. Incompatibility indicated that het gene differences were present on that linkage group. Each linkage group was tested in turn using a small number of different progeny strain pairings. Thus rare parasexual recombinants which had arisen by the disruption of the linkage between a het gene, or genes, and the marker gene on the same chromosome, could be detected and not confound the assay.

Although the $\mathrm{h}-\mathrm{cQ} / \mathrm{h}-\mathrm{cGl}$ hybrid was not heterozygous for the marker on linkage group VI it was still possible to complete the chromosome assay. Subsequent sexual crosses of selected parasexually derived progeny strains with h-cGl strains established the number of het gene locations on each linkage group (Dales \& Croft, 1983). It was shown that the h-cQ strain differed from $h-c G l$ strains at five het loci. Two genes were detected on linkage group III and one gene on each of linkage groups $\mathrm{V}, \mathrm{VI}$ and VII.

This chromosome assay method followed by selected sexual crossing has now been used to investigate the number and location of het genes acting between a strain of $\mathrm{h}-\mathrm{cA}$ and an $\mathrm{h}-\mathrm{cGl}$ master strain.

\section{Methods}

Strains. The strains of $A$. nidulans used are described in Table 1.

Media. Czapek $(\mathrm{Cz})$ medium was derived from the formula of Thom \& Church (1926). The ingredients per litre were: $\mathrm{NaNO}_{3}, 2.0 \mathrm{~g} ; \mathrm{KCl}$, $0.5 \mathrm{~g} ; \mathrm{MgSO}_{4} .7 \mathrm{H}_{2} \mathrm{O}, 0.5 \mathrm{~g} ; \mathrm{ZnSO}_{4} .7 \mathrm{H}_{2} \mathrm{O}, 0.01 \mathrm{~g} ; \mathrm{K}_{2} \mathrm{HPO}_{4}, 1.0 \mathrm{~g}$; $\mathrm{FeSO}_{4} .7 \mathrm{H}_{2} \mathrm{O}, 0.01 \mathrm{~g}$; sucrose, $30.0 \mathrm{~g}$; agar (Oxoid no. 3), $15.0 \mathrm{~g}$. This medium was used routinely as a minimal medium. Auxotrophic strains were cultured on $\mathrm{Cz}$ supplemented with the particular nutrient(s) required. The ability to utilize lactose as the sole carbon source was tested by using $\mathrm{Cz}$ medium in which lactose $\left(10.0 \mathrm{~g} \mathrm{I}^{-1}\right)$ was used in place of sucrose.

Strain culture. General culture methods and methods for the production and analysis of sexual crosses were derived from those of Pontecorvo et al. (1953) and Clutterbuck (1974). Methods for heterokaryon compatibility testing, the isolation, fusion and regeneration of protoplasts, the haploidization of diploid strains, and the detection of het genes by chromosome assay have been described previously (Dales \& Croft, 1977, 1983; Dales et al., 1983).

Terminology. Throughout this paper the terms compatible and incompatible will mean heterokaryon compatible and heterokaryon incompatible respectively.

\section{Results and Discussion}

Protoplast fusion of strains 7-141 (h-cG1) and 65-5 (h-cA)

Dense protoplast suspensions $\left(>5 \times 10^{6}\right.$ protoplasts $\mathrm{ml}^{-1}$ ) were prepared from strains 7-141 and 65-5. These 


\section{Table 1. Strains of A. nidulans}

Strains 7-37 and 7-141 are members of $\mathrm{h}-\mathrm{cGl}$ and are derivatives of NRRL 194. Strain 7-141 is FGSC 375. Gene symbols and locus letters are as defined by Clutterbuck (1974). Strain 65-5 is a UVinduced mutant derivative of wild isolate 65 in the Birmingham strain collection and is a member of $\mathrm{h}-\mathrm{cA}$. A sexual cross with wild isolate 65 (data not shown) generated only a low frequency of aneuploid types among the progeny. This suggests that strain 65-5 is translocation-free (Pollard et al., 1968; Upshall \& Käfer, 1974) with respect to wild isolate 65 . Gene symbols are as defined by Clutterbuck (1974). Locus letters are arbitrary, e.g. paba-65.1 represents the first para-aminobenzoic acid (PABA) requiring mutant to be isolated from wild isolate 65. Roman numerals indicate linkage group.

\begin{tabular}{|c|c|}
\hline $\begin{array}{l}\text { Birmingham collection } \\
\text { strain no. }\end{array}$ & Genotype \\
\hline $7-37$ & $\underset{\text { I }}{p a b a A 6, y A 2}$ \\
\hline $7-141$ & 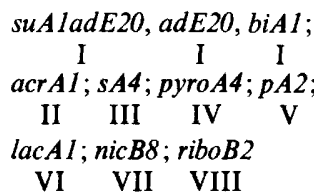 \\
\hline $65-5$ & $\begin{array}{c}\text { paba-65.1, } \\
\text { I }\end{array}$ \\
\hline
\end{tabular}

were mixed in approximately equal concentrations as estimated by haemocytometer counts and induced to fuse by treatment with polyethylene glycol $(30 \%, \mathrm{w} / \mathrm{v}, \mathrm{PEG}$ 4000 in $0.1 \mathrm{M}-\mathrm{CaCl}_{2}$ ) as described by Dales \& Croft (1977). The protoplast fusion mix was plated out on osmotically stabilized agar $(\mathrm{Cz}+0.6 \mathrm{M}-\mathrm{KCl})$ in soft agar overlays and incubated at $35^{\circ} \mathrm{C}$. Small colony centres composed of just a few hyphae were visible on these plates after $3 \mathrm{~d}$ incubation. Several hundred such colony centres regenerated but on prolonged incubation the majority showed no further mycelial growth and excreted a dark-red pigment into the surrounding agar. Only 12 colony centres showed continued growth and after $7 \mathrm{~d}$ incubation these colonies showed the fan-shaped sectors that are characteristic of nutritionally complementing, balanced heterokaryons (Dales \& Croft, 1977, 1983; Dales et al., 1983). The mycelium of these colonies, though, was severely affected when compared with balanced heterokaryons from compatible pairings and was composed of a loose network of hyphae with most of the growth being below the agar surface. A dark-red pigmentation developed within these hyphae and diffused into the surrounding agar. The sparse hyphae on the agar surface produced very few conidiophores and the sporeheads produced were small, watery and unpigmented.

A total of 350 small agar block subcultures were made both from the 12 sectoring-growth colonies and by complete transfer of non-sectoring colony centres to fresh plates of $\mathrm{Cz}$ agar. Of these 350 inoculations only 17 showed a sectoring growth pattern and these were all subcultures from the 12 original sectoring growth colonies.

The 17 colonies on $\mathrm{Cz}$ agar were morphologically similar to the 12 colonies on $\mathrm{Cz}+0.6 \mathrm{M}-\mathrm{KCl}$ agar. The mycelial growth was again mainly below the agar surface, occasionally surfacing to form small regions of aerial growth. Consequently, the colonies appeared to be composed of discrete clumps of surface mycelium separated by bare agar surface. This effect was accentuated as the subsurface hyphae were deeply pigmented due to the accumulation of red pigment, while the aerial hyphae were hyaline. The rare conidial heads were again small, watery and generally unpigmented, though faint pale-green or yellow sporeheads were occasionally observed. Striped heterokaryotic conidial heads were not detected.

Subcultures to plates of $\mathrm{Cz}$ agar fully supplemented for all the auxotrophic markers carried by both of the parental strains, i.e. the removal of nutritional selection, led to the growth of vigorous sectors of both parental phenotypes. Analysis of these sectors confirmed that they were parental genotypes and indicated the probable heterokaryotic nature of the colonies from which these sectors arose, though it was possible that the 17 colonies could have been mixed cultures of the original parental strains that were complementing on minimal medium by cross-feeding.

A dense suspension of conidia and hyphal fragments was prepared from the aerial clumps of the sectoring growth colonies on $\mathrm{Cz}$ agar. This suspension was plated in soft agar overlays on fresh plates of $\mathrm{Cz}$ agar. After $4 \mathrm{~d}$ incubation at $35^{\circ} \mathrm{C}$ a confluent lawn of pink-pigmented mycelium was produced on all of the plates. Single-spore purifications gave rise to symmetrically round colonies of thin, pink-pigmented mycelium that was stable on transfer to fully supplemented agar. Sporehead formation was rare, though all were pale green. The mean conidial diameter was larger $(\sim 1.3 \times)$ than that of haploid conidia. These pink colonies were assumed to be diploid and a single culture (RD15) was retained for further analysis.

\section{Haploidization and chromosome assay}

Small agar blocks were cut from a colony of strain RD15, transferred to plates of fully supplemented $\mathrm{Cz}$ agar containing $1.0,1 \cdot 1,1 \cdot 2,1.3,1.4$ or $1.5 \mu \mathrm{g}$ Benlate (E. I. du Pont de Nemours) $\mathrm{ml}^{-1}$, and incubated at $35^{\circ} \mathrm{C}$ for $5 \mathrm{~d}$ to induce haploidization. These transfers produced normal (wild-type) green, normal yellow as well as pale-green and pale-yellow spored sectors from restricted colony 
centres at all the Benlate concentrations used. This segregation of conidial colour was good evidence for the hybrid nature of the RD15 strain and, by extrapolation, of the heterokaryotic nature of the 17 colonies isolated following protoplast fusion.

A parasexual progeny sample of 300 segregants (RD15-1 to RD15-300) was collected by subculturing from the sectors produced on the Benlate-containing plates. Only one segregant sector per colony centre was sampled to avoid re-isolating the same, or the reciprocal product, of a single haploidization event. The segregants were purified by spreading to give single colonies. An inoculum from each purification spread was collected onto $4 \times 4$ master plates and replicated onto a range of differential media to analyse the segregation of standard markers (Tables 2, 3 and 4). The master plates were also inoculated onto fully supplemented $\mathrm{Cz}$ agar containing $1.5 \mu \mathrm{g}$ Benlate $\mathrm{ml}^{-1}$ to test whether the segregants were haploid (Upshall et al., 1977). This test, in combination with conidial diameter measurements (data not shown), indicated that nine of the progeny strains were still diploid and these have been excluded from further analysis.

Tables 2 and 3 show that all of the remaining 291 progeny strains were wild-type for the lacA marker on linkage group VI. This indicates that RD15 is a recombinant diploid in which structural homozygosity has been achieved for part, or all, of chromosome VI. Similar observations have been reported for $h-c B / h-c G l$ and $\mathrm{h}-\mathrm{cQ} / \mathrm{h}-\mathrm{cGl}$ diploids (Dales et al., 1983; Dales \& Croft, 1983). It is suspected that het gene heterozygosity on this linkage group can generate a strong selective

Table 2. Segregation of standard markers among the 291 parasexual progeny derived from the recombinant diploid $R D 15$

Strain RDI5 was obtained by protoplast fusion of strains $65-5$ and 7-141. The genotype classes recovered are numbered in parentheses and the number of progeny strains obtained for each genotype class are presented.

\begin{tabular}{|c|c|c|c|c|c|c|c|c|c|}
\hline \multirow{4}{*}{$\begin{array}{l}\text { III } \\
s A 4\end{array}$} & \multirow{4}{*}{$\begin{array}{c}\text { IV } \\
\text { pyroA4 }\end{array}$} & \multirow{4}{*}{$\begin{array}{c}\mathrm{V} \\
p A 2\end{array}$} & \multirow{4}{*}{$\begin{array}{c}\mathrm{VI} \\
\text { lac } A J\end{array}$} & \multirow{4}{*}{$\begin{array}{c}\text { VII } \\
n i c B 8\end{array}$} & \multirow{4}{*}{$\underset{\text { riboB2 }}{\text { VIII }}$} & \multicolumn{4}{|c|}{ I } \\
\hline & & & & & & \multicolumn{4}{|c|}{ paba-65.1 y-65.1+ bi + paba $+^{\gamma} b i A 1$} \\
\hline & & & & & & \multicolumn{2}{|r|}{ II } & \multicolumn{2}{|c|}{ II } \\
\hline & & & & & & + acr & $a c r A I$ & + acr & acr $A l$ \\
\hline+ & + & + & + & + & + & (48) 3 & (47) 2 & & \\
\hline+ & + & + & + & + & ribo & 4 & & (75) 6 & (87) 2 \\
\hline+ & + & + & + & nic & + & & & & \\
\hline+ & + & + & + & nic & ribo & (26) 2 & (20) 2 & (61) 2 & (71) 2 \\
\hline+ & + & $p$ & + & + & + & (49) 1 & & & \\
\hline+ & + & $p$ & + & + & ribo & (6) 5 & (18) 1 & (81) 2 & (83) 1 \\
\hline+ & + & $p$ & + & nic & + & (33) 1 & & & \\
\hline+ & + & $p$ & + & nic & ribo & (25) 3 & & (74) 1 & 1 \\
\hline+ & pyro & + & + & + & + & (45) 12 & (4) 3 & (55) 3 & (57) 2 \\
\hline+ & pyro & + & + & + & ribo & (9) 2 & (8) 3 & (84) 3 & (86) 2 \\
\hline+ & pyro & + & + & nic & + & (30) 2 & (29) 3 & (92) 5 & (97) 2 \\
\hline+ & pyro & + & + & nic & ribo & (2) 6 & (40) 2 & (67) 2 & (73) 2 \\
\hline+ & pyro & $p$ & + & + & + & (46) 4 & (1) 9 & (56) 3 & (51) 2 \\
\hline+ & pyro & $p$ & + & + & ribo & (5) 3 & (13) 2 & 2 & (85) 3 \\
\hline+ & pyro & $p$ & + & nic & + & (34) 4 & (31) 1 & 3 & (93) 2 \\
\hline+ & pyro & $p$ & + & nic & ribo & (42) 4 & (23) 6 & (72) 2 & (59) 5 \\
\hline$s$ & + & + & + & + & + & (50) 1 & & & \\
\hline$s$ & + & + & + & + & ribo & (16) 3 & & (88) 1 & \\
\hline$s$ & + & + & + & nic & + & & & & \\
\hline$s$ & + & + & + & nic & ribo & (3) 2 & & (60) 1 & (62) 1 \\
\hline$s$ & + & $p$ & + & + & + & & & & \\
\hline$s$ & + & $p$ & + & + & ribo & (11) 2 & (7) 7 & (78) 2 & (80) 2 \\
\hline$s$ & + & $p$ & + & nic & + & (35) 2 & & & \\
\hline$s$ & + & $p$ & + & nic & ribo & (43) 1 & (39) 2 & (68) 2 & (66) 2 \\
\hline$s$ & pyro & + & + & + & + & (44) 2 & (24) 2 & (52) 1 & (58) 2 \\
\hline$s$ & pyro & + & + & + & ribo & (12) 5 & (15) 2 & (77) 6 & (79) 6 \\
\hline$s$ & pyro & + & + & nic & + & (32) 5 & (37) 1 & (91) 4 & 4 \\
\hline$s$ & pyro & + & + & nic & ribo & (27) 3 & (41) 2 & (65) 8 & (63) 3 \\
\hline$s$ & pyro & $p$ & + & + & + & (22) 6 & (19) 2 & 2 & (54) 1 \\
\hline$s$ & pyro & $p$ & + & + & ribo & (14) 2 & (17) 3 & (76) 4 & (82) 4 \\
\hline$s$ & pyro & $p$ & + & nic & + & (36) 1 & (28) 2 & (96) 1 & (94) 2 \\
\hline$s$ & pyro & $p$ & + & nic & ribo & (21) 7 & (38) 6 & (64) 6 & (70) 5 \\
\hline
\end{tabular}


Table 3. Segregation of alleles among the 291 parasexual progeny derived from the recombinant diploid RD15

Chi-square $\left(\chi^{2}\right)$ tests of significance were done using Yates correction. The probability levels are abbreviated as follows: * probability $(P)$ between 0.05 and $0.01 ;{ }^{* *} P$ between 0.01 and $0.001 ;{ }^{* * *} P$ less than 0.001 ; NS represents non-significance $(P$ greater than 0.05 )

\begin{tabular}{|c|c|c|c|}
\hline Alleles & $\begin{array}{c}\text { Nos of } \\
\text { progeny strains }\end{array}$ & $\chi^{2}$ & Significance \\
\hline$+^{\gamma}: y-65.1$ & $130: 161$ & 3.09 & NS \\
\hline$+^{\text {paba }}: p a b a-65.1$ & $130: 161$ & 3.09 & NS \\
\hline biAl: + bi & $130: 161$ & 3.09 & NS \\
\hline $\operatorname{acr} A 1:+^{\mathrm{acr}}$ & $121: 170$ & $7 \cdot 92$ & $* *$ \\
\hline$s A 4:+^{s}$ & $141: 150$ & 0.22 & NS \\
\hline pyro A4: + pyro & $219: 72$ & $73 \cdot 25$ & $* * *$ \\
\hline$p A 2:+^{p}$ & $147: 144$ & 0.01 & NS \\
\hline $\operatorname{lac} A 1:+$ lac & $0: 291$ & $289 \cdot 00$ & $* * *$ \\
\hline nicB8 : + nic & $138: 153$ & 0.67 & NS \\
\hline riboB2: $+^{\text {ribo }}$ & $183: 108$ & $18 \cdot 82$ & $* * *$ \\
\hline
\end{tabular}

disadvantage (Dales \& Croft, 1983). Apart from lacA, biased allelic ratios were observed for acr $A$, pyro $A$ and riboB (Table 3). These probably reflect differential allele viability. The allelic segregation of $a d E$ was masked by the presence of the suppressor of adenine requirement (suAladE20). All the progeny were prototrophic for adenine and so segregations for $a d E$ and suAladE20 could not be included in Tables 2, 3 and 4 .

Linkage was detected between the $y-65, p a b a-65$ and biA loci on linkage group I as was expected (Table 4). Linkage was also indicated for $a c r A$ with $p A, a c r A$ with $l a c A$, and $s A$ with $r i b o B$. It is unlikely that linkage is involved, though, as haploidization should lead to the assortment of complete linkage groups (McCully \& Forbes, 1965). Mitotic recombination should only disrupt such linkages in approximately $1 \%$ of haploidization events (Käfer, 1961, 1977). Values as high as $43.3 \%$ $(a c r A: p A), 41 \cdot 6 \%(a c r A: l a c A)$ and $42 \cdot 6 \%(s A: r i b o B)$

Table 4. Pairwise segregation of markers among the 291 parasexual progeny derived from the recombinant diploid RD15

$\chi^{2}$ tests were done and probability levels indicated as described for Table 3 .

\begin{tabular}{|c|c|c|c|c|c|}
\hline \multirow[b]{2}{*}{ Marker pair } & \multicolumn{2}{|c|}{ Progeny nos } & \multirow{2}{*}{$\begin{array}{l}\text { Recombination } \\
\text { frequency }\end{array}$} & \multirow[b]{2}{*}{$\chi^{2}$} & \multirow[b]{2}{*}{ Significance } \\
\hline & Parental & Recombinant & & & \\
\hline$y-65: p a b a-65$ & 291 & 0 & 0.000 & $289 \cdot 00$ & $* * *$ \\
\hline$y-65: b i A$ & 291 & 0 & 0.000 & 289.00 & $* * *$ \\
\hline$y-65: a c r A$ & 156 & 135 & 0.464 & 1.37 & NS \\
\hline$y-65: s A$ & 160 & 131 & 0.450 & 2.69 & NS \\
\hline$y-65:$ pyroA & 146 & 145 & 0.498 & 0.00 & NS \\
\hline$y-65: p A$ & 134 & 157 & 0.540 & 1.66 & NS \\
\hline$y-65: \operatorname{lac} A$ & 161 & 130 & 0.447 & 3.09 & NS \\
\hline$y-65:$ nicB & 159 & 132 & 0.454 & $2 \cdot 32$ & NS \\
\hline$y-65:$ ribo $B$ & 160 & 131 & 0.450 & 2.69 & NS \\
\hline$a c r A: s A$ & 151 & 140 & 0.481 & 0.34 & NS \\
\hline acrA :pyroA & 143 & 148 & 0.509 & 0.06 & NS \\
\hline$a c r A: p A$ & 165 & 126 & 0.433 & 4.96 & * \\
\hline acr $A: \operatorname{lac} A$ & 170 & 121 & 0.416 & 7.92 & ** \\
\hline$a c r A: n i c B$ & 148 & 143 & 0.491 & 0.06 & NS \\
\hline$a c r A:$ riboB & 145 & 146 & 0.502 & 0.00 & NS \\
\hline$s A: p y r o A$ & 151 & 140 & 0.481 & 0.34 & NS \\
\hline$s A: p A$ & 155 & 136 & 0.467 & $1 \cdot 11$ & NS \\
\hline$s A: \operatorname{lac} A$ & 150 & 141 & 0.485 & 0.22 & NS \\
\hline$s A: n i c B$ & 158 & 133 & 0.457 & 1.98 & NS \\
\hline$s A:$ riboB & 167 & 124 & 0.426 & 6.06 & * \\
\hline pyroA : pA & 143 & 148 & 0.509 & 0.06 & NS \\
\hline pyroA : lacA & 72 & 219 & 0.753 & $73 \cdot 25$ & $* * *$ \\
\hline pyroA : nicB & 156 & 135 & 0.464 & 1.37 & NS \\
\hline pyroA : riboB & 131 & 160 & 0.550 & 2.69 & NS \\
\hline$p A: \operatorname{lac} A$ & 144 & 147 & 0.505 & $0 \cdot 14$ & NS \\
\hline$p A:$ nicB & 150 & 141 & 0.485 & 0.22 & NS \\
\hline$p A: r i b o B$ & 157 & 134 & 0.460 & 1.66 & NS \\
\hline $\operatorname{lac} A: n i c B$ & 153 & 138 & 0.474 & 0.67 & NS \\
\hline$l a c A:$ riboB & 108 & 183 & 0.629 & 18.82 & $* * *$ \\
\hline$n i c B: \operatorname{riboB}$ & 156 & 135 & 0.464 & 1.37 & NS \\
\hline
\end{tabular}


Table 5. Heterokaryon compatibility tests between selected pairs of strains to test for het gene interaction

\begin{tabular}{|c|c|c|c|c|c|c|c|}
\hline $\begin{array}{l}\text { Linkage } \\
\text { group } \\
\text { under } \\
\text { test }\end{array}$ & $\begin{array}{c}\text { Strain } \\
\text { pair }\end{array}$ & $\begin{array}{l}\text { Genotype } \\
\text { class* }\end{array}$ & $\begin{array}{c}\text { Compatibility } \\
\text { test } \dagger\end{array}$ & $\begin{array}{c}\text { Linkage } \\
\text { group } \\
\text { under } \\
\text { test }\end{array}$ & $\begin{array}{l}\text { Strain } \\
\text { pair }\end{array}$ & $\begin{array}{l}\text { Genotype } \\
\text { class* }\end{array}$ & $\begin{array}{c}\text { Compatibility } \\
\text { test } \dagger\end{array}$ \\
\hline I & $\begin{array}{l}\text { RD15-29 } \\
\text { RD15-170 } \\
\text { RD15-35 } \\
\text { RD15-181 } \\
\text { RD15-26 } \\
\text { RD15-271 } \\
\text { RD15-57 } \\
\text { RD15-210 } \\
\text { RD15-45 } \\
\text { RD15-237 }\end{array}$ & $\begin{array}{l}10 \\
75 \\
26 \\
61 \\
25 \\
74 \\
45 \\
55 \\
38 \\
70\end{array}$ & $\begin{array}{l}+ \\
+ \\
+ \\
+ \\
+\end{array}$ & V & $\left\{\begin{array}{l}\text { RD15-45 } \\
\text { RD15-190 } \\
\text { RD15-59 } \\
\text { RD15-237 } \\
\text { RD15-29 } \\
\text { RD15-189 } \\
\text { RD15-63 } \\
\text { RD15-210 } \\
\text { RD15-151 } \\
\text { RD15-192 }\end{array}\right.$ & $\begin{array}{l}38 \\
63 \\
41 \\
70 \\
10 \\
81 \\
46 \\
55 \\
36 \\
91\end{array}$ & $\begin{array}{l}- \\
- \\
- \\
- \\
-\end{array}$ \\
\hline II & $\left\{\begin{array}{l}\text { RD15-45 } \\
\text { RD15-193 } \\
\text { RD15-29 } \\
\text { RD15-231 } \\
\text { RD15-1 } \\
\text { RD15-214 } \\
\text { RD15-3 } \\
\text { RD15-182 } \\
\text { RD15-53 } \\
\text { RD15-272 }\end{array}\right.$ & $\begin{array}{r}38 \\
64 \\
10 \\
87 \\
1 \\
56 \\
56 \\
3 \\
62 \\
44 \\
58\end{array}$ & $\begin{array}{l}- \\
- \\
- \\
- \\
-\end{array}$ & VI & $\left\{\begin{array}{r}\text { RD15-237 } \\
7-37 \\
\text { RD15-245 } \\
7-37 \\
\text { RD15-284 } \\
7-37 \\
\text { RD15-45 } \\
7-141 \\
\text { RD15-84 } \\
7-141\end{array}\right.$ & $\begin{array}{l}70 \\
70 \\
70 \\
38 \\
38\end{array}$ & $\begin{array}{l}- \\
- \\
- \\
- \\
-\end{array}$ \\
\hline III & $\left\{\begin{array}{l}\text { RD15-45 } \\
\text { RD15-174 } \\
\text { RD15-30 } \\
\text { RD15-189 } \\
\text { RD15-29 } \\
\text { RD15-234 } \\
\text { RD15-3 } \\
\text { RD15-181 } \\
\text { RD15-7 } \\
\text { RD15-171 }\end{array}\right.$ & $\begin{array}{r}38 \\
59 \\
11 \\
81 \\
10 \\
88 \\
3 \\
31 \\
61 \\
19 \\
51\end{array}$ & $\begin{array}{l}- \\
- \\
- \\
- \\
-\end{array}$ & VII & $\left\{\begin{array}{l}\text { RD15-45 } \\
\text { RD15-196 } \\
\text { RD15-29 } \\
\text { RD15-181 } \\
\text { RD15-57 } \\
\text { RD15-191 } \\
\text { RD15-50 } \\
\text { RD15-240 } \\
\text { RD15-32 } \\
\text { RD15-210 }\end{array}\right.$ & $\begin{array}{r}38 \\
82 \\
10 \\
61 \\
45 \\
92 \\
7 \\
66 \\
30 \\
55\end{array}$ & $\begin{array}{l}- \\
- \\
- \\
- \\
-\end{array}$ \\
\hline IV & $\left\{\begin{array}{l}\text { RD15-45 } \\
\text { RD15-240 } \\
\text { RD15-88 } \\
\text { RD15-210 } \\
\text { RD15-127 } \\
\text { RD15-214 } \\
\text { RD15-59 } \\
\text { RD15-182 } \\
\text { RD15-46 } \\
\text { RD15-237 }\end{array}\right.$ & $\begin{array}{l}38 \\
66 \\
48 \\
55 \\
49 \\
56 \\
41 \\
62 \\
39 \\
70\end{array}$ & $\begin{array}{l}+ \\
+ \\
+\end{array}$ & VIII & $\left\{\begin{array}{l}\text { RD15-13 } \\
\text { RD15-237 } \\
\text { RD15-88 } \\
\text { RD15-172 } \\
\text { RD15-57 } \\
\text { RD15-217 } \\
\text { RD15-168 } \\
\text { RD15-234 } \\
\text { RD15-59 } \\
\text { RD15-212 }\end{array}\right.$ & $\begin{array}{l}28 \\
70 \\
48 \\
75 \\
45 \\
84 \\
50 \\
88 \\
41 \\
95\end{array}$ & $\begin{array}{l}+ \\
+ \\
+ \\
+ \\
+\end{array}$ \\
\hline
\end{tabular}

* Genotype classes are derived from Table 2.

$\dagger+$, Compatibility;,- incompatibility.

must, therefore, reflect distortions from random segregation. Distorted pairwise segregations were also obtained for pyroA and riboB with lacA. In both cases excess recombinant types were recovered. These unexpected segregations may reflect chance variation or sampling error compounded with differential allele viability. Despite deviations from 50:50 ratios the observed segregations suggest a translocation-free relationship between the h-cA and h-cGl parental strains with the possible exception of linkage group VI.
Pairs of progeny strains were selected (Table 5) that differed for chromosome I markers. This provided a spore colour difference for compatibility testing. Five such pairs of strains were used that carried identical combinations of alleles for the markers on linkage groups II to VIII. These were tested for compatibility to screen for het gene interaction on linkage group I. No het genes were detected on this linkage group (Table 5). Other sets of five pairs of strains carried allelic differences for each of the markers on linkage groups II, III, IV, V, VII and 
Table 6. Sexual crosses done to establish the number of het gene differences operating on linkage groups II, III, V,VI, and VII between the parental strains 65-5 and 7-141, of h-cA and $h-c G I$ compatibility respectively

\begin{tabular}{|c|c|c|c|c|c|c|c|}
\hline \multirow{3}{*}{$\begin{array}{l}\text { Cross } \\
\text { number }\end{array}$} & \multirow{3}{*}{$\begin{array}{l}\text { Strains } \\
\text { crossed* }\end{array}$} & \multirow{3}{*}{$\begin{array}{c}\text { Linkage } \\
\text { groups } \\
\text { under } \\
\text { test }\end{array}$} & \multirow{3}{*}{$\begin{array}{l}\text { Total } \\
\text { progeny } \\
\text { sample }\end{array}$} & \multicolumn{2}{|c|}{$\begin{array}{l}\text { Compatibility } \\
\text { classes }\end{array}$} & \multirow{3}{*}{$\begin{array}{l}\text { No. of } \\
\text { het } \\
\text { genes }\end{array}$} & \multirow{3}{*}{$\begin{array}{l}\text { Linkage } \\
\text { group } \\
\text { location }\end{array}$} \\
\hline & & & & Parental & \multirow[t]{2}{*}{ Recombinant } & & \\
\hline & & & & $\overline{A \quad G l}$ & & & \\
\hline RD24 & $\begin{array}{c}\text { RD15-237 } \times 7-37 \\
(70)\end{array}$ & VI & 100 & 47,53 & & 1 & VI \\
\hline RD25 & $\begin{array}{c}\text { RD15-193 } \\
(64)\end{array}$ & II and VI & 64 & 16,19 & $\begin{array}{l}15,14 \\
15,14,6\end{array}$ & 2 & VI, II \\
\hline RD26 & $\begin{array}{c}\text { RD15-174 } \times \text { (59) } \\
\text { 7-37 }\end{array}$ & III and VI & 102 & 16,17 & $\begin{array}{l}17,9,8 \\
28,29\end{array}$ & 3 & VI, III, III \\
\hline RD27 & ${ }_{(63)}^{\text {RD15-190 }} \times$ 7-37 & $\mathrm{V}$ and $\mathrm{VI}$ & 100 & 19,24 & 21,29 & 2 & VI, V \\
\hline RD28 & $\begin{array}{c}\text { RD15-196 } \times 7-37 \\
(82)\end{array}$ & VI and VII & 97 & 26,21 & 21,29 & 2 & VI, VII \\
\hline
\end{tabular}

* The numbers in parentheses denote genotype class (derived from Table 2).

VIII in turn. These strains were compatibility tested to screen for het gene activity on each of these linkage groups. The lack of segregation for linkage group VI prevented the selection of strain pairs from within the RD15 progeny that carried alternative alleles at the lac $A$ locus. Two progeny genotype classes were detected that carried marker alleles derived from the h-cGl parent (7141) on all linkage groups except VI (genotype class 70) or I and VI (genotype class 38). Representatives of these two genotype classes were compatibility tested with the h-cGl strains $7-37$ or 7-141, respectively, to test for het gene interaction on linkage group VI. The results presented in Table 5 show that het genes were segregating among the RD15 progeny on linkage groups II, III, V, VI and VII.

Determination of the total number of het gene differences between the parental strains 65-5 and 7-141

Selected RD15 progeny strains were backcrossed to the h-cGl strain 7-37. Progeny samples were purified, collected onto $4 \times 4$ master plates and genotyped for standard markers and compatibility. The crosses and the numbers of progeny compatibility classes generated are presented in Table 6 . These indicate a total of six het gene differences between the original parental strains $65-5$ and 7-141. Two of these differences are located on linkage group III and one on each of linkage groups II, V, VI and VII.

These results are similar to those obtained previously from the analysis of a hybrid strain produced by protoplast fusion of an h-cQ strain (106-2) and an h-cGl master strain (7-21), where five het gene differences were detected (Dales \& Croft, 1983). No het gene location was detected on linkage group II between these h-c groups. Whether any of the het genes on linkage groups III, V, VI and VII in h-cA strains are identical to, or allelic with, the het genes on the corresponding linkage groups of $h$ $\mathrm{cQ}$ strains has not yet been determined.

We acknowledge the Science Research Council for the award of a research grant to J.H.C.

\section{References}

BUTCHER, A. C. (1968). The relationship between sexual outcrossing and heterokaryon incompatibility in Aspergillus nidulans. Heredity 23, 443-452.

CATEN, C. \& JinKS, J. L. (1966). Heterokaryosis: its significance in wild homothallic Ascomycetes and Fungi Imperfecti. Transactions of the British Mycological Society 49, 81-93.

Clutterbuck, A. J. (1974). Aspergillus nidulans. In Handbook of Genetics, vol. 1, pp. 447-510. Edited by R. C. King. New York: Plenum Press.

CROFT, J. H. \& Jinks, J. L. (1977). Aspects of the population genetics of Aspergillus nidulans. In Genetics and Physiology of Aspergillus, pp. 339-360. Edited by J. E. Smith \& J. A. Pateman. London: Academic Press.

Dales, R. B. G. \& Croft, J. H. (1977). Protoplast fusion and the isolation of heterokaryons and diploids from vegetatively incompatible strains of Aspergillus nidulans. FEMS Microbiology Letters 1, 201-203.

Dales, R. B. G. \& Croft, J. H. (1983). A chromosome assay method for the detection of heterokaryon incompatibility (het) genes operating between members of different heterokaryon compatibility (h-c) groups in Aspergillus nidulans. Journal of General Microbiology 129, 3643-3649.

Dales, R. B. G., Moorhouse, J. \& Croft, J. H. (1983). The location and analysis of two heterokaryon incompatibility (het) loci in strains of Aspergillus nidulans. Journal of General Microbiology 129, 36373642. 
GrINDLE, M. (1963a). Heterokaryon compatibility of unrelated strains in the Aspergillus nidulans group. Heredity 18, 191-204.

GRINDLE, M. (1963b). Heterokaryon compatibility of closely related wild isolates of Aspergillus nidulans. Heredity 18, 397-405.

Jinks, J. L., Caten, C. E., Simchen, G. \& Croft, J. H. (1966). Heterokaryon incompatibility and variation in wild populations of Aspergillus nidulans. Heredity 21, 227-239.

KÄFER, E. (1961). The process of spontaneous recombination in vegetative nuclei of Aspergillus nidulans. Genetics 46, 1581-1609.

KäFER, E. (1977). Meiotic and mitotic recombination in Aspergillus and its chromosomal aberrations. Advances in Genetics 19, 33-131.

MCCULLY, K. S. \& ForBes, E. (1965). The use of $p$-fluorophenylalanine with 'master strains' of Aspergillus nidulans for assigning genes to linkage groups. Genetical Research 6, 352-359.

Pollard, R., KäFer, E. \& Johnston, M. (1968). Influence of chromosomal aberrations on meiotic and mitotic non-disjunction in Aspergillus nidulans. Genetics 60, 743-757.
Pontecorvo, G., Roper, J. A., Hemmons, L. M., MacDonald, K. D. \& Bufton, A. W. J. (1953). The genetics of Aspergillus nidulans. Advances in Genetics 5, 141-238.

ROPER, J. A. (1966). Mechanisms of inheritance: the parasexual cycle. In The Fungi, vol. 2, pp. 589-617. Edited by G. C. Ainsworth \& A. S. Sussman. New York: Academic Press.

ThOM, C. \& CHURCH, M. (1926). The Aspergilli. Baltimore: Williams \& Wilkins.

THOM, C. \& RAPER, K. B. (1945). A Manual of the Aspergilli. Baltimore: Williams \& Wilkins.

UPSHALl, A. \& KÄFER, E. (1974). Detection and identification of translocations by increased specific non-disjunction in Aspergillus nidulans. Genetics 76, 19-31.

UPSHALl, A., GidDings, B. \& MoRTimore, I. D. (1977). The use of Benlate for distinguishing between haploid and diploid strains of Aspergillus nidulans and Aspergillus terreus. Journal of General Microbiology 100, 413-418. 